\title{
Yang Liuzhuang express drone application and development study
}

\author{
Linguang Wang*, and Jinghui Yao
}

School of E-commerce and Logistics, Beijing Technology and Business University, Beijing, 100048, China

\begin{abstract}
This paper presents a feasibility study on the application of delivery drones in Yang Liu Zhuang. In order to make the cost calculation convincing, the article realistically simulates the delivery scenario of Yang Liu Zhuang during the epidemic, and then analyzes its transportation cost in depth, and finally concludes that using drones to partially replace traditional delivery in Yang Liu Zhuang can save costs and improve logistics efficiency. However, at present, the delivery by express drones is mainly limited by their own load weight, and they cannot deliver medium and large goods.
\end{abstract}

Keywords: Logistics, Courier drones, Costing, UAV.

\section{Introduction}

In recent years, with the rise of e-commerce and the development of the logistics industry, the rapid rise of the courier industry, the community for the timeliness of delivery is doubly important. Especially in rural and mountainous areas, the infrastructure construction is not perfect, resulting in long delivery time and low efficiency. Because of the high cost of building infrastructure, a large number of logistics companies embarked on drone delivery to achieve the results of reducing delivery costs and expanding the scope of delivery.

\section{Yang Liu Zhuang scene breakdown}

This paper calculates the delivery cost according to the delivery of $30 \mathrm{~kg}$ goods, and strictly simulates Yang Liu Zhuang in traditional delivery as well as express drone delivery scenarios.

(1) Express drones and car delivery targets are distinguished. Car delivery requires delivery to the customer's request located in the main road location, or come to the main road delivery vehicle to personally pick up, and the express drone is responsible for delivering the goods to the designated location and notifying the customer to pick up on

*Corresponding author: 1446548365@qqq.com 
their own. But the distance difference between the pickup location and the customer can be ignored.

(2) Express drones only target Yang Liu Zhuang perimeter for delivery. During the epidemic, the situation of closed villages and closed roads courier drones only for Yang Liu Zhuang perimeter for distribution. Other locations in temporarily ignored, in fact, if the courier drone delivery range is wider, can cover the villages within $10 \mathrm{~km}$, the situation is more favorable for the drone. Jingdong shipping point to Yang Liu Zhuang's receiving location is $2 \mathrm{~km}$.

(3) Express UAV dispatch system can be offset with the bridge fee for vehicle delivery. According to Google Maps as well as the actual situation examined, during the epidemic distribution to and from Yang Liu Zhuang requires $200 \mathrm{~km}$ of rugged roads, and can only be distributed to villages that can be reached, and cannot be directly deposited, making parcel distribution difficult. The following assumes that it can be distributed to Yang Liu Zhuang. Which car distribution process considering bridge fees and excessive car damage from the road can be offset with each other due to the initial development costs of the logistics drone scheduling system. (In fact the development cost of the dispatching system in companies with multiple sites is very little, and such systems are replicable and negligible in the operational phase. The road and bridge costs incurred per vehicle per day are higher than the cost of the logistics drone dispatch system per site).

(4) courier drones can operate automatically without manual labor during operation. No additional manual operation is required, only the dispatcher needs to monitor the operational status of the courier drone.

(5) Neither courier drones nor automobiles take into account the associated costs. Neither courier drones nor automobiles take into account the associated maintenance costs insurance costs, personnel learning costs costs and other miscellaneous costs.

(6) Depreciation calculation method and the number of years. The depreciation cost of the car is calculated in accordance with 8 years, the depreciation cost of the courier drone is calculated in accordance with 3 years, and the battery of the courier drone is calculated in accordance with 300 times of cyclic discharge. The car depreciation used temporarily ignore the cost of tire depreciation.

(7) The number of parcels delivered. After the author's telephone interview learned that during the epidemic Yang Liu Zhuang Zhoubian parcel quantity is 14 / piece per day, the total weight does not exceed $30 \mathrm{~kg} /$ day.

(8) Express UAVs need to purchase additional internal batteries due to work requirements. The courier drone carries 6 batteries at the time of purchase and needs to purchase 6 additional lithium batteries for each flight. By avoiding the time lost in charging, it can be used to accelerate the efficiency of delivery. The straight-line distance from the delivery station to the destination is $4 \mathrm{~km}$. 


\section{Costing}

Table 1. Cost comparison and calculation method.

\begin{tabular}{|c|c|c|c|c|c|c|}
\hline $\begin{array}{l}\text { Distribution } \\
\text { tools }\end{array}$ & $\begin{array}{l}\text { Purchasin } \\
\text { g fixed } \\
\text { costs }\end{array}$ & $\begin{array}{l}\text { Hardware } \\
\text { Commuted } \\
\text { Cost (days) }\end{array}$ & $\begin{array}{l}\text { Electricity/ } \\
\text { Postage } \\
\text { (days) }\end{array}$ & $\begin{array}{l}\text { Driver cost } \\
\quad \text { (days) }\end{array}$ & $\begin{array}{l}\text { Comprehe } \\
\text { nsive cost } \\
\text { (days) }\end{array}$ & Cost per kg \\
\hline $\begin{array}{c}\text { Wuling } \\
\text { Hongguang } \\
\text { 201820181. } \\
\text { 5Lclassic } \\
\text { modelSbasi } \\
\text { c type } \\
\end{array}$ & 46800 & 16.027 & 83.52 & 150 & 249.547 & 8.3 \\
\hline $\begin{array}{l}\text { DJI Drone } \\
\text { M600 }\end{array}$ & 46000 & 151.1 & 12 & 0 & 163.1 & 5.43 \\
\hline \multicolumn{7}{|c|}{$\begin{array}{l}\text { Remark. } \\
\text { 1. Amount unit: Yuan } \\
\text { 2. The service life of the courier drone is about } 300 \text { days } \\
\text { 3. Car cost quotation for the car home quotation } \\
\text { 4. The price of } 92 \text { gasoline used in the car is calculated according to } 4.8 \text { yuan } \\
\text { 5. The fuel consumption of the car is } 8.7 \mathrm{~L} \text { per } 100 \mathrm{~km} \text { according to the data of the car home. } \\
\text { 6. Express UAV according to M } 600 \text { data for the flight } 4 \mathrm{~km} / \text { degree electricity cost of } 1 \text { yuan / } \\
\text { degree } \\
\text { 8. Calculated on the basis of delivery of goods not exceeding } 30 \mathrm{~kg} \text { per day }\end{array}$} \\
\hline \multicolumn{7}{|c|}{$\begin{array}{l}\text { The calculated cost of car distribution is as follows: } \\
\text { (1) Purchase fixed cost: } 46,800 \text { yuan } \\
\text { (2) Hardware conversion cost/day: } 46800 / 8 / 365=16.027 \text { yuan } \\
\text { (3) Fuel cost/day: } 4.8 * 8.7 *(200 / 100)=83.52 \text { yuan } \\
\text { (4) Driver's salary/day: } 150 \text { yuan } \\
\text { (5) Total cost of car distribution: } 16.027+83.52+150=249.547 \text { yuan } \\
\text { (6) Cost per kilogram: } 249.547 / 30=8.3 \text { yuan }\end{array}$} \\
\hline \multicolumn{7}{|c|}{$\begin{array}{l}\text { The calculated costs for drone delivery are as follows. } \\
\text { (1) Purchase fixed cost: } 46,000 \text { yuan } \\
\text { (2) Hardware conversion cost/day: }(40,000-6 * 1000) / 3 / 365+(6+6) * 1000 /(300 /(30 / 5 / 2))=151.1 \\
\text { yuan } \\
\text { (3) Electricity cost/day: }(30 / 5)=12 \text { yuan } \\
\text { (4) Driver's salary/day: } 0 \text { yuan } \\
\text { (5) Total cost of drone delivery: } 151.1+6+0=163.1 \text { yuan } \\
\text { (6) Cost per kilogram: } 157.1 / 30=5.43 \text { yuan }\end{array}$} \\
\hline
\end{tabular}

Table 2. Cost of using the vehicle in combination with the ferry.

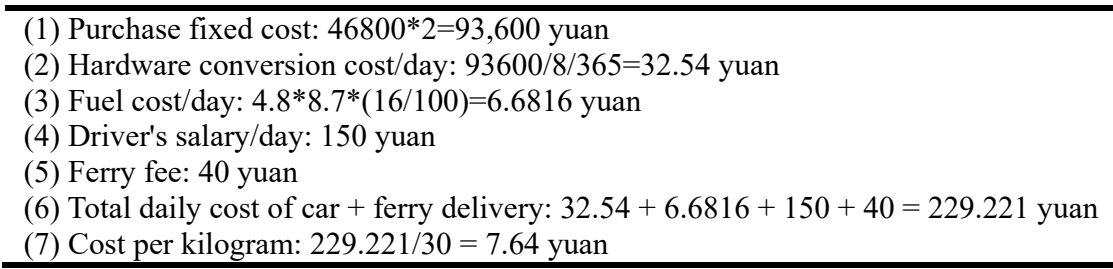

\section{Analysis of results}

It is assumed that three types of distribution methods exist in the Yang Liu Zhuang area under normal circumstances. 
(1): The distribution station uses vehicles to distribute in and around Yang Liu Zhuang throughout the whole process, and its distribution cost is RMB 8.3/per kilogram.

(2): Delivery stations use express drones for delivery, and their delivery cost is 5.43 $\mathrm{RMB} /$ per $\mathrm{kg}$.

(3): the distribution station uses two vehicles combined with a ferry boat, and its distribution cost is $\$ 7.64 /$ per $\mathrm{kg}$.

It can be seen that the distribution cost comparison is: express drone distribution < vehicle-ship combined distribution $<$ vehicle distribution

According to the above calculation method, during the normal period, with the increase of the number and weight of the single delivery of goods by the car, the cost per kilogram advantage of the courier drone will be reduced by the influence of the range and its own weight, and will eventually be greater than the cost per kilogram of delivery by the car.

\section{Conclusion}

Although the delivery advantages of express drones are obvious: they can ignore ground infrastructure construction; cross lakes; do not require manual operation; save delivery costs; and improve delivery efficiency. But the development of express drones does have a series of problems: range needs to be further addressed; low-altitude management is conservative for the application of express drones, etc. Such calculations are performed under ideal conditions, and if the volume of the package to be sent is greater than $0.5 \mathrm{~m}^{2}$ or the single weight is greater than $5 \mathrm{~kg}$, it will have an impact on the flight of the courier drone and increase the uncertainty on the way of delivery.

\section{References}

1. Xu Hongfei. Research on logistics UAV trajectory planning for intelligent obstacle avoidance [D]. Beijing Jiaotong University,2019.

2. Jia-Cheng Tang. Research on collaborative UAV delivery algorithm under multiple constraints [D]. Shenyang University of Aeronautics and Astronautics,2019.

3. Song Yue. Research and simulation analysis of HTN-based UAV mission planning [D]. Beijing University of Posts and Telecommunications, 2019.

4. Zhao Lin-Tian. Research on the legal regulation of public safety of drones [D]. China University of Mining and Technology,2019.

5. Duan Fanli. Research on logistics UAV swarm delivery and pickup route planning problem based on improved teaching optimization algorithm[D]. Chang'an University,2019.

6. Jiao ZL, Lv XH, Liu BG. Design of a regulatory system for the drone logistics industry based on the whole industry chain[J]. China Science and Technology Forum,2019(11):38-47.

7. Farsijani S, Cauley J A, Santanasto A J,Glynn N W,Boudreau R M,Newman A B. Transition to a More Even Distribution of Daily Protein intake Is Associated with Enhanced Fat Loss during a Hypocaloric and Hhysical Activity Intervention in Obese Older Adults. [J]. The journal of nutrition, health \&amp; aging,2020,24(2).

8. Qun Liu, Daqing Jiang, Tasawar Hayat, Ahmed Alsaedi. Stationary Distribution and Extinction of a Stochastic HIV-1 Infection Model with Distributed Delay and Logistic Growth[J]. Journal of Nonlinear Science,2020,30(1). 
9. Yao Gang. Research on urban and rural goods delivery to home based on OTO model [J]. Cooperative Economy and Technology,2020(03):78-79

10. Bow Yanrong, Feng Lixin, An Cuiguo, Zhang Xinyong. An introduction to the application of drones [J]. Academic Research of Shijiazhuang Polytechnic Vocational College, 2019,14(Z2):24-26+38. 